\title{
Por los senderos de la justicia indígena boliviana
}

\section{Un dialogo con la Amawt'a Marcela Quisbert}

Por Roger Adan Chambi Mayta

\section{Resumo}

O exercício do pluralismo jurídico boliviano nas mãos dos povos indígenas demonstrou as contradições do que está estipulado na lei com a prática. A experiência da Amawt'a Marcela Quisbert, principal líder no primeiro processo de Conflito de Competência entre a Jurisdição Camponesa Indígena Original e a Jurisdição Ordinária levantada no Vale do Zongo, é um testemunho dos limites que as autoridades indígenas cruzam na época de exercer seus direitos coletivos no quadro normativo plural. A partir disso, nesta entrevista, pretendemos divulgar este cenário de conflito e as diferentes estratégias de resistência que emergiram das autoridades indígenas, uma vez que foram dirigidas pelas formalidades da Jurisdição Ordinária.

Palavras-chave: Pluralismo jurídico; Conflito de Competição; Autoridades Indígenas.

\section{Resumen}

El ejercicio del pluralismo jurídico boliviano de la mano de los pueblos indígenas ha demostrado las contradicciones de lo estipulado en la ley con la práctica. La experiencia de la Amawt'a Marcela Quisbert, dirigente principal dentro del primer proceso de Conflicto de Competencias entre la Jurisdicción Indígena Originaria Campesina y la Jurisdicción Ordinaria suscitada en el valle de Zongo, es testimonio de los límites que las autoridades indígenas atraviesan a la hora de ejercer sus derechos colectivos en el marco normativo plural. A partir de ella, en esta entrevista pretendemos dar a conocer ese escenario de conflicto y las distintas estrategias de resistencia que emergieron desde las autoridades indígenas al verse direccionados por los formalismos de la Jurisdicción Ordinaria.

Palabras-clave: Pluralismo jurídico; Conflicto de Competencia; Autoridades Indígenas.

1 Maestrante en el Programa Interdisciplinar em Estudos Latino-Americanos (PPG-IELA), de la Universidade Federal da Integração Latino-Americana (UNILA) 
A partir de la vigencia de la nueva Constitución Política del Estado de Bolivia (CPE), la administración de la justicia boliviana abre paso al pluralismo jurídico y con ella a nuevos mecanismos y disposiciones jurídicas que van, al menos en teoría, en favor de los Pueblos Indígenas Originarios Campesinos (PIOC). La CPE establece que "la función judicial es única en Bolivia" (Art. 179) y que esta justicia se divide en cuatro jurisdicciones: la Jurisdicción Ordinaria (JO), la Jurisdicción Agroambiental (JA), la Jurisdicción Especial (JE) y la Jurisdicción Indígena Originaria Campesina (JIOC), aclarando que todas ellas gozan de igualdad jerárquica y que entre las cuatro debe existir respeto, cooperación y coordinación. Sin embargo, a más de diez años de la nueva $\mathrm{CPE}$, la aplicabilidad y funcionamiento de la JIOC en la resolución de problemas específicos, son escasos y dificultosos por el poco ejercicio que se han hecho de ellas, puesto que la normativa que por una parte reconoce derechos a los pueblos indígenas, por otra parte los priva en el momento del ejercicio de su jurisdicción, dejando en el vacío los conceptos de "igualdad", “cooperación”, "coordinación" y reproduciendo con ello la predominancia del derecho positivo grecorromano y monista.

Dentro los pocos procesos de resolución de conflictos en materia de JIOC, el caso más significativo aconteció en la comunidad indígena de Cahua Grande, ubicado en el valle de Zongo del departamento de La Paz, donde las autoridades sindicales indígenas, mediante voto resolutivo de asamblea, en fecha 19 de julio de 2010, decidieron expulsar al empresario minero Oscar Bellota, dueño de la mina "Alexander", por contaminación al ecosistema de la comunidad y por distintos abusos de falta de pagos y beneficios salariales que este cometía contra los trabajadores mineros pertenecientes del mismo pueblo. La expulsión provocó la reacción del empresario minero denunciando, por la JO, a todas las autoridades indígenas que habían firmado su expulsión, alegando los delitos de robo agravado, daño calificado, asociación delictuosa, allanamiento de domicilio, amenazas y lesiones ${ }^{3}$, logrando que tres de las autoridades indígenas fueran apresadas por el lapso de dos años.

Este hecho dio paso a la primera disputa de competencias dentro del marco normativo plurinacional, donde por un lado se vieron autoridades indígenas que (aunque en un principio no sabían el procedimiento legal) pedían respeto al ejercicio de la JIOC y, por otro lado, el empresario minero amparado por sus abogados denunciando desde la JO. Este conflicto desmanteló la superficialidad de lo estipulado en la normativa plurinacional en favor de los PIOC, ya que las autoridades indígenas de Zongo, en el momento de la práctica, en el ejercicio de sus derechos, se vieron limitados por normativas que empequeñecían sus atribuciones como autoridades, teniendo que someterse a formalismos y a la verticalidad de la justicia ordinaria para hacer valer su competencia en la resolución de sus propios conflictos.

A partir del año 2016, se realizaron trabajos etnográficos y socio-jurídicos sobre el proceso

2 Mina de explotación del mineral "scheelita", ubicada en la misma comunidad del Valle de Zongo,

3 Sentencia Constitucional Plurinacional 0874/2014, Sucre, 12 de mayo de 2014. 
de conflicto de competencia de los PIOC de Zongo ${ }^{4}$. En esta oportunidad abordamos este caso significativo del testimonio de Marcela Quisbert Pillco, quien fue autoridad sindical durante el conflicto contra el empresario minero Oscar Bellota y que en la actualidad sigue disputando en favor de la JIOC como amawt' $a^{5}$ y miembro del Tribunal Originario Abya Yala de Justicia (TOAJ). Así pues, lo que sigue es una conversación realizada el 25 de octubre de 2018 en inmediaciones de la sala de reuniones del TOAJ, ubicada a pocas cuadras de la Plaza Murillo de la ciudad de La Paz.

Sentados en el suelo, Marcela Quisbert (MQ) saca de su bolso un $\operatorname{tari}^{6}$ con hojas de coca para iniciar la conversación. La puerta de la oficina está abierta y por fuera se ve el anochecer con aguacero. Mientras pijchamos ${ }^{7}$, empezamos el dialogo.

Entonces ¿una vez que en el ampliado se resuelve expulsar al señor Oscar Bellota, él con sus papeles en mano dijo que la mina y los terrenos eran suyos?

Marcela Quisbert (MQ): En el ampliado, lo que él ha presentado ha sido eso. Dijo que él ya estaba documentado. Tenía documentos de compra de cada comunario de Cahua Grande, y tenía documentos de Cahua Chico que del patrón había comprado. Entonces, los que vivían ahí no eran nada. Eso es lo que él decía. "Como tengo papeles, ustedes como organización sindical agraria no se pueden meter, porque ustedes no saben lo que están diciendo, yo tengo documentación", así nos ha dicho.

\section{Hablando con otros comunarios, me enteré que él había comprado los terrenos de forma engañosa, ¿acaso las victimas de esas compras no se han manifestado?}

MQ: Se han manifestado, por eso cuando él dijo eso, nosotros le hemos dicho, “¿con que permiso has comprado? Porque las tierras comunitarias no son de venta, no se vende, porque las tierras comunitarias manejan las comunidades. Las sayañas ${ }^{8}$ sí es de los comunarios, pero ni eso se puede vender, porque son tierras comunitarias". Entonces eso es lo que nosotros le hemos planteado. Le hemos dicho, "usted siendo un ingeniero, como es posible que diga que se ha comprado, ¡no está a la venta, eso no se vende!”. Entonces, allí él dijo que "nosotros éramos unos ignorantes, que no deberíamos meternos en esos asuntos". Eso causó la expulsión de él. Porque hemos visto, había abuelitos temblando con bastón, hoy en día ya murieron, que habían trabajado

4 Revisar: PACHAGUAYA, Pedro; MARCANI, Carlos Etnografia de un litigio interlegal: la defensa jurídica desde la jurisdicción indígena en Bolivia. 2016; COPA, Magali Vianca, Dispositivos de ocultamiento en tiempos de pluralismo jurídico en Bolivia. Tesis de Maestría de la Universidad Autónoma de San Luis Potosí, 2017.

5 Terminología aymara y quechua para referirse a la persona con cargo alto que tiene amplios conocimientos en diferentes niveles de la vida, el que tiene sabiduría.

6 Tejido indígena Aymara para llevar la hoja de coca

$7 \quad$ Acto ritual de masticar las hojas de coca.

8 Parcela individual dentro de la comunidad. Lugar donde se vive y se cría ganado. 
en su mina y nunca les ha jubilado, nunca les ha asegurado, les descontaba sus pagos diciendo que están asegurados, pero cuando alguien estaba mal e iban al seguro no existía ningún documento, nunca hubo ningún seguro. Eso fue un tema fuerte también para la expulsión. Entonces, todo eso se ha demandado y ahí estaban los demandantes, los hermanos y todavía una hermana llorando dijo que su hijo trabajaba en la mina y cuando se accidentó le botaron de la mina, le botaron al camino sin importarle si vive o muere, entonces, todas esas quejas hubo en pleno ampliado. A raíz de todo eso la gente reacciona y dice pues, "¡basta!, "ya no podemos seguir así en Zongo, ya no puede seguir habiendo patrones, ¡tiene que irse ese señor!". Por esa situación es la expulsión al Oscar Bellota, no es por otra cosa, sino es por esa situación. De esa manera empieza ese problema en Zongo.

\section{¿Una vez expulsado que dijo Oscar Bellota, que acciones tomó?}

MQ: Él nos trató de ignorantes y el pueblo se ha enaltecido y pidió que el secretario de justicia lo cargue y le dé su chicotazo ${ }^{9}$, entonces el secretario de justicia ya se estaba yendo, entonces por orden del pueblo lo agarran a Oscar, lo cargan y le dan dos chicotazos delante de todos, y le dicen que esperen ahí, hasta que salga la resolución, y Oscar con toda su gente estaba esperando, delante de él se hace la resolución de expulsión, le dijeron que "!ahora te vas a ir de Zongo, una vez que termine el ampliado no queremos verte en la mina, te vas!”. “iTú no eres zongueño, no queremos verte más!“

\section{¿Acaso él no tenía casa en Zongo?}

MQ: Tiene casa, ha vivido hartos años, pero él es del departamento de Oruro. Por todos los maltratos le hemos dicho "te vas, no te queremos ver", eso fue el mandato del pueblo. Y después ellos se retiran con todo su grupo de mineros también, nosotros como autoridades nos quedamos hasta muy tarde resolviendo otros temas, hemos terminado como siete de la noche, hasta llegar a la mina ha debido ser las ocho. Llegamos a la mina, todo había estado cerrado con candado. Un rato nosotros paramos con el carro y dijimos "ya se había ido", y nos hemos venido, hemos dicho en esta semana hay que venir para hacer inventario y todo lo que está pasando, dijimos como autoridades de la Central. Nos venimos y a la semana llega la citación de la Fiscalía, llega citación del Defensor del Pueblo, llega citación del Ministerio de Gobierno, del Ministerio de Mina, y así, donde pudo Oscar Bellota ha ido a quejarse. ¿Qué dijo? había dicho que le habíamos wasqueado ${ }^{10}$ nosotros como zongueños a un mayor de edad desde el pueblo de Huaji hasta Huayna Potosí, que en movilidad la distancia es cuatro horas, que le habíamos traído de rodillas a chicotazos. ¿Qué

9 Según Marcelo Fernández Osco en Prácticas del derecho indígena originario en Bolivia (2009), el castigo con chicote es un tipo de sanción física indígena aymara para delitos de carácter público. 
humano puede aguantar semejante barbaridad? ¡Nadie! Pero su mentira era así, fatal. Y le dieron un impedimento de cincuenta días.

\section{¿En su certificado de médico forense?}

MQ: Sí, otro que mintió también. Y así con todo eso nos hicieron el proceso. Primero a cinco personas, y cuando fuimos al Defensor del Pueblo, ahí es cuando empiezan a incluirnos a otras personas más. A todos aquellos que estábamos defendiendo. Por ejemplo la Central ya estaba, yo como era de la Central Agraria, segunda autoridad como Sub Central, entonces yo tuve que tomar la defensa. Y cuando veníamos al Ministerio de Gobierno, nos decían pues en el Ministerio "uy, qué bien ustedes han hecho cumplir sus sentencias" y luego nos dicen que para la segunda reunión con el minero más nos vamos a reunir. En la segunda reunión, en el Ministerio, el minero Oscar estaba bien sentado con sus abogados, nosotros llegamos con toda la gente y no nos dejan entrar, solo entramos unos cinco o seis, así nomás ya, nos dicen que ese tanto nomás podemos entrar, y los demás hermanos esperaban afuera, nosotros hemos entrado como comisión. Y nos dicen, "miren hermanos, ustedes han cometido un error en Zongo. En primer lugar ustedes no son dueño de las minas, es del Estado, por lo tanto ustedes han hecho mal, no debían expulsar, no debían hacer esto, nunca debían tocar a un mayor de edad, que la justicia comunitaria no debiera hacer eso, eso está mal”, y así. Todo eso ya cambia la figura en explicarnos. Y ahí yo le dije, ahora hablo bien el castellano, esa ves no, por eso en Aymara le hablé, "mira hermano, al principio ustedes nos dicen que ¡uy!, que bien que hemos hecho valer nuestras resoluciones, nos dijeron que estaba excelente, y ahora que está aquí el minero con todos sus abogados ustedes dicen que hemos hecho mal. Entonces ¿de qué sirve la Constitución Política del Estado? ¿Por qué hemos luchado?, ¿Por qué han muerto nuestros hermanos por la Asamblea Constituyente?, ¡hemos luchado por tierra y territorio, nosotros somos ancestros, somos dueños de tierra y territorio!, ¿qué les pasa hermanos?”. Y después el Ministro de Gobierno dice "esta hermana piensa que no les estoy entendiendo pero la entiendo, yo entiendo Aymara", después él me contesta en idioma Quechua. Yo le digo que no estamos en Oruro ni en Cochabamba ${ }^{11}$, y el sigue diciendo “yo entiendo, me estás insultando, me estás diciendo que yo estoy a favor del minero, y por lo tanto rompo esta audiencia y no hay más". Así ha sido, así nos ha abandonado el Ministerio de Gobierno. Entonces, al día siguiente, yo ya estoy incluido en el proceso, supuestamente por haber insultado, por incitar y todas esas cosas, hasta ahora sigo en ese proceso.

\section{¿Hasta ahora sigue en ese proceso?}

MQ: Sigo, ocho años estamos en proceso. Entonces eso pasa, nos aumentan en el proceso a otros cinco dirigentes más. Fuimos al Defensor de Pueblo, entonces llega Zongo con todas las

11 Departamentos de Bolivia donde se habla generalmente el idioma quechua como lengua indígena. 
autoridades, ahí estamos reunidos para reunirnos con el Defensor del Pueblo, la cita era para las nueve, nosotros ya estábamos ahí a las siete por que los hermanos del campo madrugamos pues, no andamos tarde, entonces, ya estábamos en la plaza. Entonces, viene una guarnición de policías, ¿y qué nos dice? “¡donde está el Angel Sullca, quien es Angel Sullca!” nosotros ya nos hemos dado cuenta que nos están viniendo a buscar, dijimos que no conocemos, aunque el Angel Sullca estaba ahí, pero dijimos que no conocíamos, después dijeron “donde está la Lorena”, o sea a los cinco hermanos estaban buscando.

\section{¿Por qué específicamente se estaba buscando a estas personas?}

MQ: La Central Agraria era Angel Sullca, el que ha pegado con chicote era Callizaya, la Lorena era pues Secretaria General de la comunidad Cahua Grande y René Magueño era Secretario General de Cahua Chico, a ellos primero estaban buscando. Ya había orden de aprensión ¿Por qué? porque cuando nos ha llegado la citación, nosotros fuimos donde un abogado, y al abogado le hemos dicho ¿Qué vamos a hacer? El abogado nos dice, "no le den importancia, es la primera citación, en la segunda se van a presentar". Mentira había sido eso, porque para la segunda ya había estado con mandato de apremio para ese día. En pleno Defensor de Pueblo nos querían hacer agarrar a los cinco hermanos para llevar adentro y hacernos callar, ese había sido su estrategia del que tiene plata. Entonces, nosotros les hemos escondido a los hermanos y ahí los policías a la fuerza nos querían hacer hablar y a la hermana Lorena le habían querido quitar la maleta con todos los libros de actas de ampliados, le querían quitar hasta la $w a w a^{12}$. Pero como éramos hartos y en ese lugarcito había pues para vender frutas y cosas así, los hermanos zongueños no tenían nada pues para defenderse, los hermanos zongeños vinieron para reunirse con el defensor, pero la policía vino bien preparada. Entonces los hermanos zongueños agarraron las frutas de las que vendían de la plaza y con eso le dieron a la policía, y ha sido un enfrentamiento fuerte. El Defensor del Pueblo en vez que nos abra la puerta nos lo ha cerrado, y ahí ha sido un problema muy fuerte, después nos abren y nos hacen entrar, todo el día estábamos ahí, hasta las seis de la tarde, hasta que no pueda tener valor su documento, entonces recién salimos. Ahí firma el minero diciendo que no nos va a procesar ya, eso ha dicho en el Defensor del Pueblo, se comprometió a no procesarnos.

\section{¿Hicieron una conciliación?}

MQ: Ahí le hemos dicho "¿cómo pues te vamos a hacer llevar de rodillas desde Huaji hasta el Huayna Potosí? Ningún humano aguanta eso, no es posible tanta mentira, si ahora mismo estas de pie, nadie aguanta de rodillas, ni una cuadra, ahí es arcilloso el camino, no puede aguantar nadie". Entonces todo eso hemos aclarado y con todo eso se ha arreglado, hemos conciliado.

12 Terminología aymara para referirse a los niños o recién nacidos. 


\section{¿Y en que quedaron en el Defensor del Pueblo?}

MQ: Hemos quedado en que él iba a levantar todos los procesos y después íbamos a volver a reunirnos en Zongo, pero ¿Qué pasó? Ni bien hemos terminado, nos ha vuelto hacer perseguir, no ha respetado al Defensor del Pueblo, tengo yo su informe del Defensor del Pueblo. Entonces, el Defensor del Pueblo ha sido parte también pues de hacernos atacar con la Policía, como son tan cobardes no nos han ayudado, perdón, pero yo así les veo. Entonces, desde ahí hemos terminado después con el Ministerio de Mina, por todo lado defendiendo y también con abogados, con los abogados en cada audiencia que nos citaban hemos ido a declarar, yo no me he callado, a mí me decían "cállate, no digas nada", yo decía "¿Por qué tengo que callarme?, yo no he hecho nada, al final, jamás he tocado su mina, ni conozco, ni sé, por lo tanto a mí no me puede mentir". Entonces eso fue una de las cosas más grandes que hemos tenido que enfrentar en todo ese tiempo. Viendo toda esa situación hasta este momento, pasando con todas estas cosas, recién he aprendido muchas cosas, porque nosotros al principio no sabíamos. Siempre uno tiene sus valores y sus principios y piensa que así va ser la justicia, yo al menos creía de esa manera. Nunca había ido a la policía, yo pensaba que la justicia de verdad iba a actuar, pero hemos visto que no. En ese caminar, ya, uno de los hermanos de la Central Agraria se ha cambiado de una central a otra, cuando él estaba volviendo de su comunidad, el 14 de octubre de 2012, le han agarrado en una movilidad que estaba saliendo con mineral, supuestamente, dicen, diez quintales, pero jamás hubo eso. Entonces a los hermanos le detienen casi llegando a la ciudad de El Alto, y le llevan, al día siguiente se hace audiencia y le meten a la cárcel, a las autoridades de la Central Agraria, ahí es donde hemos reaccionado, estaban nuestros abogados, si, cada uno tenía abogado, estaban, casi ocho o siete abogados, estaban en la defensa y no han hecho nada, nuestros hermanos se han ido a San Pedro ${ }^{13}$. Ahí es donde realmente nos ha tocado el corazón, hemos dicho, por lo tanto aquí los abogados no nos van a defender. Entonces ahí es cuando hemos presentado Conflicto de Competencia ${ }^{14}$. Aparte del proceso por expulsión aquí en la ciudad de La Paz, con el juez de la ciudad de El Alto, fueron detenidos por robo agravado, entonces ahí nosotros presentamos Conflicto de Competencia. Guiado también por un abogado que nos dice "ah, ustedes tienen competencia, vayan a hacer una resolución”, y nosotros decimos, “¿pero cómo?”, y el abogado nos dice "es que para la audiencia necesitamos", entonces nos reunimos nosotros, toditos, todas las autoridades sindicales, "¿qué vamos a hacer, los hermanos van a pasar adentro sino?", y hacemos nuestra resolución a lo rápido, de eso conocemos pues bien. Hicimos la resolución y le damos pues al abogado y el abogado no ha defendido pues nada sobre la resolución por que no conocía. Igualito nomás nuestros hermanos han ido adentro. Entonces nos hemos agarrado de ese documento y hemos presentado Conflicto de Competencia a una instancia superior, al Tribunal Constitucional Plurinacional (TCP), ahí

13 Recinto penitenciario de la ciudad de La Ciudad de La Paz

14 Figura jurídica de demanda al Tribunal Constitucional Plurinacional, máxima instancia de justicia en Bolivia, para que esta pueda resolver a quien compete conocer un caso específico. 
ha avanzado nuestro trabajo. Ahí ha sido nuestro inicio, pero estábamos en la nada, realmente no era nada fácil, viendo toda la situación, ver a los hermanos adentro, no era nada fácil para nosotros, había un temor muy fuerte sobre el qué va a pasar, como va ser ahora, peor nos estamos hundiendo, ¿pero los demás hermanos que han hecho? ¡Escaparse! Los que han podido irse se han ido a otros departamentos, otros se han entrado al monte, le han sacado del colegio a las wawas, de las escuelitas, y se han ido, se han escapado, prácticamente se han escapado. Entonces allí es donde Zongo ha sido quebrado cada vez más, más divididos. La gente ya no quería saber nada, estaba muy difícil poder decir algo. Zongo ha sido totalmente coartado de todo, pero nos hemos defendido así, como se puede decir, con la última esperanza que había. Ya no sabíamos qué más podemos hacer en defensa de nuestros hermanos. Entonces, nos hemos defendido hasta que ha salido el Auto Constitucional del TCP, los hermanos seguían adentro, entonces llega el Auto Constitucional, ya estábamos a punto de ser detenidos por la policía, el Auto constitucional llega el 26 de junio del 2013, y el 27 de junio era la audiencia en El Alto, para que entren cinco hermanos más a la cárcel, ya estaba listo eso, entonces, ahí yo ese día, el 26 estoy en la ciudad de Sucre, voy a averiguar el trámite y me dicen “ya está tu Auto Constitucional”, entonces recojo el día 26 y me vengo esa misma noche, porque al día siguiente era la audiencia. Entonces, llegamos aquí y los hermanos llamando, queriendo saber que va a pasar, imagínate, cuanto tiempo hemos tenido que esperar para que salga el Auto Constitucional. Entonces, estaba la gente desesperada, ya no querían presentarse a la audiencia, yo les digo, "no tengan miedo, nos presentaremos. Hay un documento que tienen que respetar". Llego de Sucre, llego directo a la Fiscalía y hago notificar, primero aquí al Tribunal con eso le hago notificar al juez a las nueve de la mañana, una vez que le hice notificar recién yo vuelvo a mi casa. En la casa un poco descanso, era para las dos de la tarde la audiencia, vuelvo a bajar, ¿qué hace el juez? ¡Instala la audiencia! A pesar de que el Auto estaba en sus manos, instala la audiencia y no nos deja hablar.

\section{¿O sea no tomó en cuenta el documento?}

MQ: ¡No nos tomó en cuenta!

\section{¿Cuál era su argumento, que dijo el juez?}

MQ: No pues, normal, no nos dejó hablar. Entonces, había un abogado que ha venido, ya no teníamos abogados en ese entonces, entonces un abogado ha venido y yo sigo pidiendo que me den la palabra, estoy agarrando el Auto pero no me hace caso, normal está instalando la audiencia, y ese abogado me quita el papel y dice "¡Aquí señor juez nos tiene que escuchar! ¿Hay este Auto y aun va seguir llevando la audiencia?". Cuando el abogado le grita recién el juez para y le manda a su secretaria "a ver, ¿hay ese Auto?", Dice, y la secretaria responde que "sí, que esta mañana ha hecho notificar". Y recién se sienta, enojado le riñe a la secretaria, eso era mentira, 
estaban fingiendo, ellos ya sabían. Luego lee el Auto y recién dice, "se suspende hasta que el Tribunal Constitucional se manifieste". Y ahí me dice el juez, "este deslinde no tiene todavía su procedimiento, por lo tanto, en vano están haciendo estas cosas, en vano estás haciendo chairo ${ }^{15}$, porque igualito nomás van a ir adentro" así me ha dicho. Yo le he dicho "pero espere pues lo que diga el Tribunal Constitucional, si ya le ha llegado un Auto Constitucional ¿Por qué sigue nos discriminas?” Le he dicho al juez Enrique Morales, y él me dice “¡yo también soy indio! ¡Soy de Caranavi ${ }^{16}$, el Deslinde Jurisdiccional no nos da potestad ${ }^{17}$ !", yo le dije "está bien hermano pero esperemos qué dice el Tribunal Constitucional”. Después de ese Auto nos llegó un poco de tranquilidad, porque hasta ahí estábamos perseguidos, todos los días estábamos vigilados. Entonces, eso ha sido la parte fundamental de poder conseguir el Auto en esa fecha. Desde el Auto hemos tenido que esperar hasta la Sentencia Constitucional donde salió a favor de nosotros, hemos tenido que esperar casi un año y más. Por ejemplo, la sentencia sale el 12 de mayo de 2014 ¿Cuánto tiempo hemos tenido que esperar? Y nuestros hermanos seguían en la cárcel de San Pedro.

\section{¿Cuántos años estuvieron adentro?}

MQ: Dos años estuvieron injustamente, porque una vez que salió el Auto nadie pues ya nos podíamos mover, estaba todo en pausa y los hermanos seguían adentro, ya no había más que hacer. Entonces esa parte ha sido bien difícil con los hermanos de Zongo hablar. Llega la Sentencia Constitucional 0874/2014 donde el TCP resuelve a nuestro favor como JIOC, eso ya había salido, nosotros no conocíamos. Cuando hemos ido a Sucre recién nos han entregado, a pesar de todas estas cosas, nos ha costado casi un tiempo. Terminamos, sale la sentencia, presentamos al juez y el juez nos dice, "¡no!, todos los obrados están en Sucre, se han ido al Tribunal Constitucional, han vuelto a mandar", hemos esperado otros tres meses hasta que vuelvan las carpetas de investigación. Hemos ido al Régimen Penitenciario, hemos ido al Ministerio de Justicia, y cada lugar nos ponían un pretexto para hacer caso a la orden del TCP. A pesar de la Sentencia hemos tenido que esperar cuatro meses para recoger a nuestros hermanos de prisión en el día de audiencia. Cuando se ha hecho el día de la audiencia, en la audiencia, nos tenía que entregar pues los cuadernos de investigación a nosotros, a Zongo, pero ¿qué hace el juez? Un sector de las autoridades sindicales indígenas se parcializa pues con el minero, entonces, el minero entra con su abogado y con los ejecutivos sindicales que estaban ya a su favor.

15 Nombre de comida típica de las zonas aymaras. El término es usado para referirse a situaciones de caos o problemáticos.

16 Región indígena de clima cálido perteneciente al departamento de La Paz

17 Ley $N^{\circ} 073$, que regula los ámbitos de vigencia entre la Justicia Indígena Originaria Campesina y las demás jurisdicciones 


\section{O sea ¿ya había autoridades sindicales indígenas que estaban a su favor?}

MQ: Sí, pero eran de la provincial, nadie de Zongo, entran así, en filita. Nosotros entramos con nuestras autoridades como Zongo y con las demás autoridades que estaban con nosotros. En la audiencia, el minero, su hijo y su abogado estaban sentados en el sector del juez, toditos, nosotros estábamos abajo, sin asiento, nosotros estamos en un rincón. Ahí se veía tanta discriminación a pesar de la Sentencia. Entonces lee el juez y dice ya enojado que "ya ha declinado, yo no lo entiendo, pero ya, voy a entregar", y le quiere entregar los carpetas de investigación a los dirigentes de la provincial que estaban a favor del minero, y nosotros la gente de Zongo éramos hartos y autoridades de todo lado, de las provincias, amawt'as, hartos eran, entonces empezamos a gritar "!cómo van a entregar a esos!" y como hemos gritado mucho, el juez de miedo se lo pasa también a mi central, mi central recibe, en $a w a y u^{18}$ le pone y se lo carga en la espalda. Y ahí dice "ya ha terminado la audiencia" y cierra y no da libertad a nuestros hermanos, estaban ahí los cuatro hermanos, no da libertad, el juez se escapa por la puerta de atrás, se escapa el minero, juntos se escapan por la puerta de atrás, nos abandonan. Los dos policías que estaban ahí le querían volver a manillar a los hermanos y Zongo no permite, Zongo se lo quitan, le han arrinconado a los policías, eran docitos nomás, a los cuatro hermanos alzados se lo sacan, hemos ganado diciendo, y se lo llevan. Afuera estábamos haciendo sahumerio en agradecimiento ${ }^{19}$, todo eso, y nosotros decíamos “¿ahora que va a pasar? ¿Qué ha hecho pues este juez?”, fuimos nuevamente a su oficina, y ahí aparece la hermana Cristina, la autoridad Magistrada de Sucre, ella había estado atrás con toda la gente, ni nosotros nos hemos dado cuenta, pero si la hemos invitado junto a otras autoridades, y ella había estado atrás, sentada, y ella aparece y me dice "hermana Marcela ¿Qué es esto?”, ya la miro y le digo "¿tú estabas aquí? ¿Has visto como son tus jueces?” le dije, "esto es una vergüenza" me respondió, y junto con ella más entramos donde el juez. Ahí la hermana Cristina le ha dicho al juez “idonde me estas llevando la justicia!, ¿qué estás haciendo?” y el juez no sabía que decir, no contaba con eso. Entonces ahí le he visto cómo el juez ha temblado como gelatina sin saber que decir, y ahí la Magistrada le dijo "¿ahora ya te han robado los cuatro detenidos, ahora a esos dos policías vas a encarcelar? ¿Qué vas a hacer? ¿Ahora esos hermanos se han ido sin documento?”, así le ha dicho. Ya han fugado pues, bajo la ley de ellos, entonces ahí recién el juez hace un documento para liberarles a los hermanos como si nunca hubieran estado dentro, ahí recién hace, ni siquiera lo hace el juez Morales, hace otro doctor, era de la departamental, él hace. Entonces ahí firma y me dice la hermana Cristina que llame a los hermanos, yo les llamo a mis autoridades y ellos estaban festejando ya listos para irse a Zongo, les hago volver, les dije que no podía llevarles de esa manera. Entonces ellos volvieron, les hemos hecho volver a San Pedro nuevamente y en la tarde los hemos sacado como si nunca hubieran estado en la cárcel. Toda esa gestión lo hemos hecho en todo el día, desde la mañana hasta la tarde, ni hemos comido nada nosotros, claro los

18 Tejido aymara usado para llevar prendas $\mathrm{u}$ otras cosas en la espalda.

19 Actos rituales de agradecimiento aymara. 
hermanos se fueron a festejar, pero nosotros como autoridades de justicia teníamos que realizar todos esos trámites para tener los documentos legales. El Ministerio de Justicia ahí sí nos ayudó, trabajó con nosotros, la viceministra estaba ahí, estaba el asesor. Correteando hasta la tarde, hemos recogido. Nosotros hemos partido de la cárcel de San Pedro casi las cinco de la tarde, sacando a nuestros hermanos realmente, hemos llegado allá con la Viceministra y la Ministra, hemos llegado al Huayna, hemos estado en ahí, hemos llegado a Llahullini, en ahí la Ministra entrega y dice "al fin hemos ganado a la justicia ordinaria, cuanto nos costó", creo que ya era nueve de la noche, recién estábamos comiendo el apthapi ${ }^{20}$, recién pudimos llevar algo a la boca.

\section{¿Ganaron a la justicia ordinaria?}

MQ: Hemos pensado que era así, lamentablemente no fue así. Pasó eso, a la semana llegó nuevamente las notificaciones del juez de La Paz, por el tema de la expulsión, como te digo, con el juez de la ciudad de El Alto ganamos, pero nosotros nos hemos olvidado de La Paz, él tampoco nos hacía citar, pensé que habíamos ganado todo, pero no, nos han vuelto a citar. Nos presentamos, presentamos la sentencia diciendo que tenemos esa declaración, ahora somos autónomos, tenemos nuestra propia justicia, pero eso no le ha importado al juez. Dos años nos ha llamado a audiencias, cada mes. Nosotros presentábamos documentos y ellos nos citaban y en dos años han sacado para juzgarnos a nosotros diciendo que la expulsión nada tiene que ver con el robo agravado que era de El Alto. Entonces ahí presentamos de nuevo Conflicto de Competencias y eso está aún en Sucre y hasta ahorita Sucre no se manifiesta, ha salido un Auto pero ahí se ha quedado, no tenemos todavía nada. Por eso yo digo, la Justicia Ordinaria no quiere respetar, no quiere soltar, no respeta las sentencias, no les importa, ellos dicen que es por el caso concreto de robo agravado, nada que ver la expulsión, entonces continuamos sigue. La lucha está a medias, no hubo resarcimiento de daños y perjuicios, el minero Oscar Bellota, por donde puede nos inicia procesos y así estamos todas las autoridades. Ya estoy cansada de todos estos procesos, ya son ocho años que estoy con estos procesos. Ahí he podido conocer a los jueces, ahí he podido conocer a los fiscales, a los abogados, que tan mañosos son, y todos son los mismo, habrá pues uno o dos que es sano, y al que es sano le incluyen al medio, ¿Por qué digo esto?, conocí algunos jueces que trabajaban en favor de la Jurisdicción Indígena y le han suspendido de su trabajo un año, por eso digo, hay gente sano, sí, pero le someten a la fuerza. Eso es lo que ha pasado, eso he podido ver, palpar, cuando vas a estos espacios te hacen dar cuenta que no vales nada, que no sabes nada. He ido a un encuentro de jueces y fiscales, me ha invitado el Tribunal Constitucional hace dos años, llegué allá y me hacen sentar como invitada y los jueces y fiscales me dicen “¿qué es pues esta señora, nosotros hemos quemado nuestra cabeza estudiando quince, veinte años para estar en este lugar, qué es pues ella? Ella misma está diciendo que no tiene estudio ¿cómo es posible que ella venga a este lugar?" ahí yo me molesté y le dije “tu estarás quince años o veinte años, pero yo más de

20 Terminología aymara que hace referencia a la forma comunitaria de comer el alimento 
cincuenta años estoy en la cancha por si acaso jugando con la justicia indígena". Y así han sido momentos difíciles, más que todo para una mujer, son varones quienes te atacan, te empiezan a trapearte y levantarse desde ahí es muy difícil, pero no imposible. Hasta este momento estamos luchando, ese es nuestro camino ahorita, nosotros decimos el thakhi ${ }^{21}$. Yo ya quisiera acabar este camino, porque realmente me siento cansada.

\section{Ocho años, hermana Marcela, es mucho tiempo.}

MQ: Ocho años no solo defendiendo a Zongo sino a toda la Jurisdicción Indígena Originaria, a todos los qollanas ${ }^{22}$ porque no quiero que pasen lo que yo he pasado, porque mi casa ha sido dividida, destrozada, mis bienes han sido totalmente acabados, hoy no tengo nada, yo digo, antes de entrar al proceso yo tenía mis llamas, tenía mi ganado, gallinas, truchas, hoy no tengo nada, ni perrito para criar, he vendido todo para querer lograr esto. Dicen "la justicia indígena es gratuita, es una maravilla gritan”, ¡mentira!, no es gratuito, porque el viaje a Sucre cuesta, la estadía en Sucre cuesta, hacer los documentos cuesta, nada es gratuito. Entre nuestras comunidades, entre nosotros si es gratuito, pero cuando te enfrentas con un empresario, cuando te enfrentas con la justicia ordinaria ya no es gratuito.

\section{Gracias por sus palabras hermana Marcela.}

MQ: Gracias por venir, jallalla ${ }^{23}$. Porque realmente, ustedes son hijos de qollanas, por sus venas corren la sangre qollana, nuestros hijos, nuestros nietos mañana verán la justicia como realmente querían nuestros ancestros, no como ahora estamos viviendo. Ese es el espíritu de nosotros. Le agradezco hermano que nos haya visitado. ;Jallalla!

¡Jallalla, hermana Marcela!

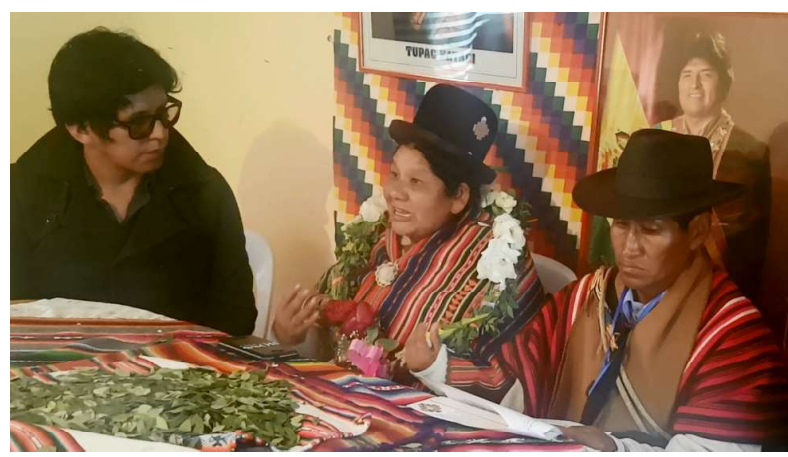

Junto a la Amawt'a Marcela Quisbert Pillco y un dirigente de la comunidad de Parcopata Fuente propia/ Comunidad indígena de Parcopata, La Paz, 25/10/2018

21 Terminología aymara que hace referencia al camino

22 Denominativo indígena de los habitantes del Qollasuyu, la actual región andina de Bolivia

23 Vitoreada en terminología aymara. 